\title{
Safety of Tattoos and Permanent Make up (PMU) Colorants
}

\author{
Eleni Andreou ${ }^{1, *}$, Sophia Hatziantoniou ${ }^{2} \mathbb{D}^{\circ}$, Efstathios Rallis $^{1}{ }^{\mathbb{D}}$ and Vasiliki Kefala ${ }^{1}$ \\ 1 Department of Biomedical Sciences, School of Health Sciences and Welfare, University of West Attica, \\ 12243 Athens, Greece; efrall@otenet.gr (E.R.); valiakef@uniwa.gr (V.K.) \\ 2 Laboratory of Pharmaceutical Technology, Department of Pharmacy, Health Sciences School, \\ University of Patras, 26504 Patras, Greece; sohatzi@upatras.gr \\ * Correspondence: elandreou@uniwa.gr
}

Citation: Andreou, E.;

Hatziantoniou, S.; Rallis, E.; Kefala, V. Safety of Tattoos and Permanent Make up (PMU) Colorants. Cosmetics 2021, 8, 47. https://doi.org/ $10.3390 /$ cosmetics 8020047

Academic Editor: Kalliopi Dodou

Received: 15 April 2021

Accepted: 2 June 2021

Published: 7 June 2021

Publisher's Note: MDPI stays neutral with regard to jurisdictional claims in published maps and institutional affiliations.

Copyright: (c) 2021 by the authors. Licensee MDPI, Basel, Switzerland. This article is an open access article distributed under the terms and conditions of the Creative Commons Attribution (CC BY) license (https:/ / creativecommons.org/licenses/by/ $4.0 /)$.

\begin{abstract}
The art of tattooing is a popular decorative approach for body decoration and has a corrective value for the face. The tattooing procedure is characterized by placing exogenous pigments into the dermis with a number of needles. The process of creating traditional and cosmetic tattoos is the same. Colorants are deposited in the dermis by piercing the skin with needles of specific shape and thickness, which are moistened with the colorant. Colorants (pigments or dyes) most of the time include impurities which may cause adverse reactions. It is commonly known that tattoo inks remain in the skin for lifetime. It is also a fact that the chemicals that are used in permanent makeup (PMU) colorants may stay in the body for a long time so there is a significant long-term risk for harmful ingredients being placed in the body. Tattoo and PMU colorants contain various substances and their main ingredients and decomposition components may cause health risks and unwanted side effects to skin.
\end{abstract}

Keywords: tattoos; permanent makeup; PMU; colorants; pigments

\section{Introduction}

Tattoos have become a very popular form of body and face art in the last two decades. There is evidence that $12 \%$ of Europeans have at least one tattoo on their body especially in the 18-35 age group [1-3]. The most common tattoos are usually made with black ink or have various colors located on almost all areas of the human body. A survey in German-speaking countries showed that in $60 \%$ of body tattoos black ink has been used [4]. When we refer to tattoos, this also includes permanent makeup (PMU), which is mostly applied over the face area. PMU is used especially on the periorbital and perioral regions for decorative reasons. PMU colorants are carefully injected with a PMU machine or by "cutting" the skin via a manual PMU procedure into the face, head and body area. These applications are made by using solid or multiple fine needles injecting the color or by placing the colorants via microblades.

Tattoo and PMU artists use tattoo colorant suspensions from different commercial suppliers in this field; chemical substances in these products are not always approved by the European Chemicals Agency (ECHA) or the Food and Drug Administration (FDA) [5]. Until recently there was no limitation on the use of certain chemicals in tattoo inks and in permanent makeup colorants. There is also no analytical method for the detection of metals, polycyclic aromatic hydrocarbons or forbidden colorants [6]. To protect European citizens, many of the hazardous chemicals found in tattoo inks and PMU are restricted in the EU under the Registration, Evaluation, Authorization and Restriction of Chemicals regulation $(\mathrm{REACH})$ will come into effect in several months [3,7]. Analytical methods focus on exactly what causes the health problems, are extremely specific. Although identifying the correct method for detecting metals in tattoo inks is particularly important, the focus should be on the actual amounts of ink injected in the skin [8]. Ink concentration into dermis is an unknown issue that should be investigated because the number of decorative tattoo 
applications has increased and the only restriction that currently exists covers chemicals that may cause cancer and genetic mutations or is focused on chemicals that are toxic to reproduction as well as skin sensitizers and irritants. If a serious restriction had been necessitated for every kind of tattooing from every country's law, many cases of chronic allergic reactions would have been prevented [9].

The aim of this review is to raise concerns about the necessity of changing regulations about tattoo ink use and ink manufacturers to make tattooing a much safer application with no cutaneous or systemic adverse effects.

\section{Methods}

The review was based on a thorough search through the literature in the relevant databases (Scopus, PubMed and Google Scholar). The search terms used, were:

1. Tattoo ink, tattoo colorants, tattoo pigments (title or abstract word), PMU pigments (title or abstract word), permanent makeup colorants (title or abstract word).

2. Adverse effects (title or abstract word), hazard (title or abstract word), side effects, complications, equipment, needles safety.

3. Tattooing, permanent makeup, microblading, micropigmentation.

Two different search groups were used. In the first group the terms were related with "or", and among each group with "and". The published material found on these databases and the World Wide Web was reviewed on the topics of safety of tattoos and permanent makeup colorants, side effects of tattoo application, and PMU application and chemical substances that might cause cutaneous adverse effects. These data were analyzed, and the results are discussed below. In Sections 3-10, information is provided about colorants and potential hazards of tattoo and PMU colorants in the human body.

\section{Tattoo Inks}

Most of tattoo inks are manufactured today in countries with national regulations over the percentages of hazardous ingredients. A short time ago, the manufacturers of inks had no regulations to follow and many of these products caused adverse reactions to the skin. Today the microbiological quality of tattoo ink and PMU products is good, and products manufactured in the EU have high production standards [10]. Ink and PMU should be produced in a sterile environment to be microbiologically stable for several months after opening. This leads to safer tattoo and PMU applications. The composition of these colorants is important because they can cause side effects such as photoallergic, granulomatous, and anaphylactic reactions. Their chemical composition can be a predictive factor of the tattoo reaction after laser treatments as well [11,12].

When finishing the tattoo or PMU application, part of the injected tattoo colorants leave the wounded skin area and an adequate amount of ink stays in the dermis area, which is the target of pigment particles in order to create the permanent result of the tattoo or PMU. The first days after a tattoo or PMU application the skin starts absorbing the colorants which remain for a long time in the injection site. As time passes pigment particles move deeper in the skin creating the permanent character of the tattoo design. This relocation from epidermis, dermis and, sometimes, subcutaneous tissue, changes the color of the tattoo as the years pass. Another unpredictable reaction of the injected tattoo colorant is their migration from the skin through the lymphatic or blood vessel system; this explains why tattoo colorants can be found in lymph nodes near the tattoo area [13].

It is estimated that every tattoo application injects about $1 \mathrm{mg}$ of ink per $\mathrm{cm}^{2}$. Scientific research in tissue samples shows that polycyclic aromatic hydrocarbons (PAHs), can be found many years after tattooing in regional lymph nodes. Azo or polycyclic compounds from colored tattoos express the same characteristics. These kinds of pigments are designed mainly for industrial use and not to be injected into human skin [14]. Due to adverse reactions, pigment compositions of certain ink colors have changed through the years [15]. For instance, toxic mercuric sulfide that was once used in red tattoos has now been removed from tattoo inks and PMU colorants because of reported skin reactions [16]. Laser removal 
is also a problem when it involves colorants with iron oxides and titanium dioxide. These chemicals are getting darker under high-powered laser treatments causing disappointment to the persons who wished to remove their tattoo [17]. Dispersive $x$-ray showed that the elemental composition of commonly used tattoo pigments, contain complex suspensions of many different chemical substances. The main ingredients of these suspensions are tiny solid particles from black, white, or colored pigments. There were also many other unknown chemical substances and a solvent. The small size of these particles is one of the reasons for the tattoo's lifetime existence on the skin [18].

\section{PMU Colorants}

PMU is made in the same way as a decorative tattoo application. The skin's outer layer is penetrated with a needle from a PMU machine or a manual PMU pen (microblading) with various numbers of needles stuck together. The colorant is injected or placed into the area beneath, with a needle angle usually at $80^{\circ}-90^{\circ}$, to make a new brow or correct the brow shape by creating brow hairs or by shading the area. The same procedure is followed for eyebrow reconstruction and modification, in the eyelid area for permanent eyeliner makeup and over the lips area in order to create a better shape and a more vivid color to the lips. The epidermis is regenerated continuously to make the PMU last and the color is injected into the dermis which is about 1.0-2.5 mm deep [19]. The application of permanent makeup is the same as the tattoo procedure and is used to produce designs that look like the aesthetic application of makeup. The quality of the results is determined by the longevity of color and the depth of colorant penetration. When the colorants are placed closed to the epidermis, they "disappear" easily after several months from application. The pigments used for PMU differ according to the procedure used. The PMU machine gives better results with inorganic colors while the manual PMU has a more "natural" result with organic colors. Every tattoo or PMU artist has to be informed about the different types of pigments and their ingredients in order to choose the right pigment color based on the technique used and the skin tone [20].

Medical tattooing is also a PMU procedure. It is used to camouflage scars or to mimic hair or nipple/areola regions after breast CA surgery, and to create micropigmentation for hair loss. PMU machines are used for medical applications because they have better results. Nowadays the application of scalp micropigmentation (SMP) in order to avoid hair transplantation has gained popularity. This technique is based on the application of PMU colors to the skin above the head area in both sexes. The micropigmentation procedure includes the use of a PMU machine, insertion of the needle at $90^{\circ}$ to the skin by shading the hair area with a dot-to-dot technique. This kind of application is made to mimic the hair follicles. When the procedure is complete, the head hair looks more plentiful and if the color is similar to the hair color, there is little difference from the natural hair. Similarly, scalp alopecia (total or partial) or scalp scars can be camouflaged with a stippling pattern of pigments that mimic the hair follicles. Due to the specificity of SPM and PMU, colorants should not fade easily as the head and face area are exposed daily to sunlight [21,22].

PMU colors have a variety of pigments that are safe, hypoallergenic and can be used either with the PMU machine or manual PMU pen (microblading) technique. They have a wide range of colors and shades that can be mixed with some restrictions in order to modify to suit the skin color [23,24]. The term pigment is used to define both the fine powder that gives color to cosmetic products such as regular makeup, as well as the solution made by adding these powders to a binder used in permanent makeup. PMU pigments are made by colored liquid concoctions. These colors stay in the skin for a period of time because of the particle size (bigger than that used in tattoo ink), which the body eventually breaks down and absorbs. This PMU application lasts from several months up to a few years so it can be applied again. PMU colorants are one of the differences between permanent makeup pigments and tattoo ink because ink has tiny particles that cannot be broken down; the ink is placed deeper into the skin during the tattoo procedure with different kind of machines. 
The tattoo will last a lifetime no matter how much the color changes over the years due to sun exposure and various other reasons $[25,26]$.

\section{Colorants}

Colorants belong to the same category as pigments or dyes with molecules that have the same chemical structure. On the other hand, dyes have pigments, which are practically insoluble in the medium in which they are incorporated. Although tattooing and PMU are injectable procedures, colorant suspensions are not pharmaceutical substances and do not have the injectable products standards. They contain over 100 different chemical compounds to different extents [27]. They are a mix of several chemicals and may contain hazardous substances that cause skin allergies and other serious health impacts, such as genetic mutations and cancer $[13,28]$. As the tattoo and PMU procedure are made by the injection in skin of such colorants, they may create health risks on every tattooed individual. Ink pigments have been found in lymph nodes and the liver after migration from the skin area [29]. The choice of pigment type depends on the PMU technique used, the artist's preference, the area of the treatment and the skin type of the client. Most of the tattoo and PMU colorants are made up of both organic and inorganic pigments. The chemical synthesis of pigments has many tiny insoluble particles, which have diameters from a few tenths of nanometers (nanoparticles) up to a few micrometers. Other kinds of finishing processes give the surfaces of the pigment particles the ability for different applications [30,31].

\section{Inorganic Pigments}

The main characteristic of inorganic pigments is the addition of iron oxide elements. As they are synthetically produced from metals, they have an inorganic character (clay, ultramarines, titanium oxide, manganese violet). They are used in tattoo and PMU applications with the use of a machine but not with the manual PMU pen (microblading). The purpose of adding iron oxides to tattoo and PMU colorants is to provide solid color and opacity and widen the shade range. Titanium dioxide prevails in lighter shades, while iron oxides prevail in darker shades. Titanium dioxide is used as a brightening agent in tattoo pigments, sunscreens and generally in paints. It has a white color and one of its most important characteristics is the absorption of UV light in the range between 280 and $400 \mathrm{~nm}[7,32]$.

Today there are a variety of inorganic pigments based on iron oxides in many colors of tattoo ink and PMU colorants. These colors are yellow, red and black, which are based on heavy metals such as mercury sulfide (red), cadmium sulfide (yellow), chromium oxide (green), or cobalt spinel (blue). They are unaffected by light, non-toxic and insoluble, which is important for the prevention of color migration. Inorganic pigments are the least likely to cause an allergic reaction and are a widely used group of pigments in permanent makeup application. This happens because they give a more stable result when they are used for shading techniques because of the tiny pigment particle distribution [33].

\section{Organic Pigments}

Tattoo colorants contain more than $80 \%$ of industrial organic pigments [7,34]. Organic pigments can be produced in a big variety of color shades ranging from green, blue, red and violet to yellow. These kinds of pigments absorb the light resulting in high color strength and have a vivid color in the skin, which lasts for a long time [35]. This characteristic makes these colorants very important for tattoo application. Polycyclic or azo pigments, as they are known, are used in tattoo colorants and are classified by their chemical constitution. Their subdivision is: mono-azo, dis-azo, b-naphtol, and naphthol AS. There are also pigments with metal complexes, which have cobalt, copper and nickel $[5,36]$.

Heterocyclic and aromatic compounds are the characteristics of polycyclic pigments; quinacridone pigments (red, bluish red, violet) and the phthalocyanines (green, blue) are representative examples [37]. The production of purely organic pigments is very small and 
is performed by a few companies in the market. The reason for this is because this kind of pigment has a complex chemical synthesis, and the colorants contain many by-products along with titanium dioxide [38]. In general, carbon is the basis of organic chemistry, so these are basically carbon derivatives. In the past, they were obtained from plant and animal organisms but that was not a safe option. This is because vegetable dyes can cause allergic reactions in many ways. Today's color production combines carbon with other substances such as oxygen and hydrogen [39].

Changing the ratios modifies color density. Hydroxide aluminum is also a substance used in tattoo and PMU colors. The main characteristic of hydroxide aluminum is that it is not a soluble substance and this leads to color retention. The pigment becomes heavier and that is the reason why it can set into the skin in a better way. The hypoallergenic formulation of the organic pigments which are manufactured today, is given by alumina hydroxide, which creates a protective membrane over the pigment molecules to prevent a direct reaction with the skin tissue. These pigments are called lake pigments [40]. Organic pigments are affected by sunlight exposure and fade easier, a characteristic, which is the reason why they are more often used in PMU applications. PMU is characterized as a semi-permanent application in contrast with the permanent tattoo application. Elemental carbon molecules are the smallest of all ingredients used in PMU; this characteristic gives a pitch-black, opaque color. Although they can be used in PMU applications, they have a high migration risk because of the small particle size [41,42]. In the last few years waterbased colorants have appeared. They have no iron oxides and contain around $45 \%$ water and are reported as purely botanic [43]. They are used for PMU applications and have a good result over the face area especially on oily skin. They are characterized as "vegan" pigments and they have gained ground in the PMU colorants market.

In Figure 1 we can see the difference between tattoo inks and PMU colors, which can be seen after diluting $1 \mathrm{~mL}$ of the colorant in water. The tiny particles of tattoo ink are spread over the glass while the PMU colorant stays at the bottom of the glass and does not mix with the water.

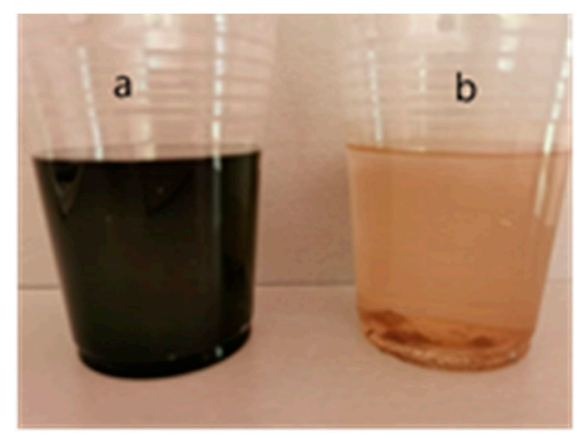

Figure 1. (a) Tattoo ink diluted in water, (b) PMU color diluted in water. Image courtesy of EleniAndreou.

\section{Potential Hazards of Tattoo Colorants}

Although tattoo and PMU colorants are being injected in the human body to a depth of $1 \mathrm{~mm}$ to $3 \mathrm{~mm}$ (Figure 2), they have no pharmaceutical guidelines referring to subcutaneous use. They cannot be categorized as cosmetic products or medicines. The exact list of ingredients, if they are referred to at all, depends on the legislation of each country about the manufacturers or importers of this kind of product, so there are significant gaps in our knowledge about their ingredients. Tattoo colorants containing hazardous chemicals have been found on the European market. In samples taken from the tattoo and PMU colorant market, microbiological contamination, heavy metals, polycyclic aromatic hydrocarbons (PAH), primary aromatic amines (PAA), and preservatives were found [7]. As the application of tattoo and PMU is administered invasively and creates skin injury, the healing process should last a few days. A survey of 3411 tattooed participants revealed that $8 \%$ of the participants still had health problems 4 weeks after tattooing, and $6 \%$ had persistent skin problems in the tattooed area $[4,5]$. There is a correlation of these problems 
with the tattoo ink, the colors and their ingredients. This was also confirmed by comparing the data of the survey with medical case reports. The results showed that colored tattoo pigments have cutaneous effects over the skin area [44].

\section{Tattoo and PMU Colourants}

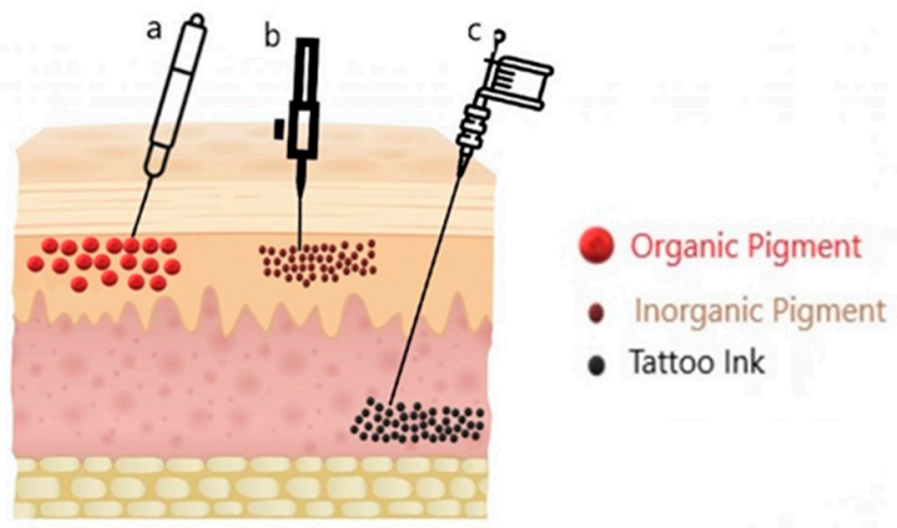

Figure 2. The depth of tattoo and PMU colorants according to organic and inorganic ink and different machine use. Inorganic pigments contain bigger particles of colorants and are placed deeper into the skin. (a) Manual PMU pen (microblading), (b) PMU machine, (c) tattoo machine. Image courtesy of Eleni Andreou.

As there are large amounts of PAH in black colorants, hazardous substances are being injected into the skin. This observation is verified by ink found in human organs even in placenta [45]. Generally, there is a lack of scientific investigations or epidemiologic data about the systemic effects of tattoo colorants and their decomposition products. The tattoo trend has led to millions of people having many, often large, tattoos over their body. The majority of these have a size of $600 \mathrm{~cm}^{2}$ or more. Such a tattoo can include about 1500 $\mathrm{mg}$ of azo pigments. These pigments are injected into the human body and there is the possibility of skin or internal organ health problems [4,46].

\section{Ink Market}

Tattoo and PMU ink markets are spread all over the world. It is estimated that $80 \%$ of tattoo inks are manufactured outside of Europe. Asian and American products used by tattoo artists have a dominant presence in the market. The pricing policy of these products vary in every country, with the Asian market being the most competitive. A percentage of $70 \%$ of permanent makeup inks are manufactured in Europe, but also many products are imported from America and Asia. In Europe, tattoo inks and PMU colorants are manufactured by about 30 companies located in Spain, Netherlands, Germany, Italy, England and France [47]. In 2008, the European Council Resolution ResAP (2008)1 was created regarding the requirements and criteria for the safety of tattoos and permanent makeup guides for the manufacturers of tattoo inks. Currently, Netherlands, Norway, France, Germany, Spain, Switzerland and Sweden have adopted national regulations on tattoo ink manufacturing and Austria, Italy, Denmark and Slovenia are using the resolution to control tattoo inks [48]. Today ink manufacturers should follow the rules of the Classification, Labelling and Packaging (CLP) Regulation in terms of labelling products that contain classified substances in excess of their classification limits and REACH in terms of registration requirements and information provision. It is still unknown what happens when ink enters the body and this need led to a prohibited ingredients list creation [49]. It is commonly accepted that forbidden ingredients for cosmetic use products cannot be used in tattoo inks and PMU colorants. Ingredients with no cosmetic regulation can be used. A prohibited list with dangerous colorants has been created in order to protect consumers [50]. This year there was an improvement according to a recent article in The Brussels Times. The European Chemicals Agency is working on a union-wide bill that will 
tackle the use of "CMR substances: carcinogenic or causing cancer, mutagenic or affecting cell development and reprotoxic, which interfere with fertility and the reproductive system" in tattooing and PMU [51]. In several months, a more condensed list of hazardous chemicals found in tattoo inks and permanent makeup under restriction by the REACH Regulation, is going to be announced in order to protect European citizens. The target is not banning tattooing procedures, but to make the color use safer [3].

\section{Conclusions}

The increasing popularity of tattoos and PMU applications expose human skin to colorants and chemical substances that can lead, in many cases, to skin and health problems. The complexity of tattoo ink compounds includes organic dyes, metals, and solvents which might have a hazardous effect on the human body. The unclear identification of tattoo inks as cosmetic products or medicines although they are injected into the skin without being authorized as sterile and injectable, is a serious issue. Recent studies show that $28 \%$ of tattooed individuals have more than four tattoos on their body, including PMU applications. The safety of tattoo inks and PMU colorants has obviously increased in Europe in the last few years. From the creation of the European Council Resolution ResAP (2008)1, which resulted in the improved quality control of pigment raw materials, significant changes have been achieved. Further scientific investigation over the tattoo issue needs to be performed. The necessity to explore the unknown long-term side effects of various inks and colorants into the skin is huge, and every country should create a strict regulation about tattoo and PMU applications. It seems obvious that important steps should be obtained over the regulations of the colorant production, which represent the basic elements of tattooing. Furthermore all tattoo artists should be properly trained to identify harmful ingredients written on the product packaging. Each country should be responsible for every tattoo and permanent makeup studio and provide lists with forbidden substances in colorants and perform random checks on ink imports.

Author Contributions: All authors (E.A., S.H., E.R., V.K.) conceived and designed the review; E.A. wrote the paper; E.R. and V.K. supervised the paper. All authors have read and agreed to the published version of the manuscript.

Funding: This review received no external funding.

Institutional Review Board Statement: Not applicable.

Conflicts of Interest: The authors declare no conflict of interest.

\section{References}

1. Giulbudagian, M.; Schreiver, I.; Singh, A.V.; Laux, P.; Luch, A. Safety of tattoos and permanent make-up: A regulatory view. Arch. Toxicol. 2020, 94, 357-369. [CrossRef]

2. Nho, S.W.; Kim, M.; Kweon, O.; Kim, S.J.; Moon, M.S.; Periz, G.; Huang, M.-C.J.; Dewan, K.; Sadrieh, N.K.; Cerniglia, N.K. Microbial contamination of tattoo and permanent makeup inks marketed in the US: A follow-up study. Lett. Appl. Microbiol. 2020, 71, 351-358. [CrossRef]

3. European Chemicals Agency. Available online: https://echa.europa.eu/hot-topics/tattoo-inks. (accessed on 10 April 2021).

4. Klugl, I.; Hiller, K.A.; Landthaler, M.; Baumler, W. Incidence of health problems associated with tattooed skin: A nation-wide survey in German-Speaking countries. Dermatology 2010, 221, 43-50. [CrossRef] [PubMed]

5. Bäumler, W. Chemical hazard of tattoo colorants. Presse Med. 2020, 49, 104046. [CrossRef]

6. Kluger, N. Epidemiology of tattoos in industrialized countries. Curr. Probl. Dermatol. 2015, 48, 6-20.

7. Piccinini, P.; Pakalin, S.; Contor, L.; Bianchi, I.; Senaldi, C. Safety of Tattoos and Permanent Make-Up: Final Report; JRC Science for policy report EUR 27947; European Commission: Brussels, Belgium, 2016.

8. Kluger, N. Cutaneous complications related to permanent decorative tattooing. Expert Rev. Clin. Immunol. 2010, 6, 363-371. [CrossRef] [PubMed]

9. Kluger, N. Cutaneous infections related to permanent tattooing. Med. Mal. Infect. 2011, 41, 115-122. [CrossRef] [PubMed]

10. Petersen, H.; Lewe, D. Chemical purity and toxicity of pigments used in tattoo inks. Curr. Prob. Dermatol. 2015, 48, 136-141.

11. Ortiz, A.E.; Avram, M.M. Redistribution of ink after laser tattoo removal. Dermatol. Surg. 2012, 38, 1730-1731. [CrossRef] [PubMed] 
12. Dirks, M. Making innovative tattoo ink products with improved safety: Possible and impossible ingredients in practical usage. Curr. Prob. Dermatol. 2015, 48, 118-127.

13. Kluger, N.; Koljonen, V. Tattoos, inks, and cancer. Lancet Oncol. 2012, 13, 161-168. [CrossRef]

14. Laux, P.; Tralau, T.; Tentschert, J.; Dahouk, S.A.; Bäumler, W.; Bernstein, E.; Bocca, B.; Alimonti, A.; Colebrook, H.; de Cuyper, C.; et al. A medical-toxicological view of tattooing. Lancet 2016, 387, 395-402. [CrossRef]

15. Kluger, N. Contraindications for tattooing. Curr. Probl. Dermatol. 2015, 48, 76-87. [PubMed]

16. Gaudron, S.; Ferrier-LeBouëdec, M.C.; Franck, F.; D'Incan, M. Azo pigments and quinacridones induce delayed hypersensitivity in red tattoos. Contact Dermat. 2014, 72, 97-105. [CrossRef]

17. Hutton Carlsen, K.; Serup, J. Patients with tattoo reactions have reduced quality of life and suffer from itch: Dermatology Life Quality Index and Itch Severity Score measurements. Ski. Res. Technol. 2015, 21, 101-107. [CrossRef]

18. Engel, E.; Vasold, R.; Santarelli, F.; Maisch, T.; Gopee, N.; Howard, P.; Landthaler, M.; Bäumler, W. Tattooing of skin results in transportation and light-induced decomposition of tattoo pigments-A first quantification in vivo using a mouse model. Exp. Dermatol. 2010, 19, 54-60. [CrossRef]

19. De Cuyper, C. Complications of Cosmetic Tattoos. Curr. Probl. Dermatol. 2015, 48, 61-70.

20. De Cuyper, C. Cosmetic and Medical Applications of Tattooing. In Dermatologic Complications with Body Art; Cuyper, C.D., Pérez-Cotapos, S.M.L., Eds.; Springer: Berlin/Heidelberg, Germany, 2009.

21. Seyhan, T.; Kapi, E. Scalp Micropigmentation Procedure: A Useful Procedure for Hair Restoration. J. Craniofacial Surg. 2021, 32, 1049-1053. [CrossRef]

22. Saed, S.; Ibrahim, O.; Bergfeld, W. Hair camouflage: A comprehensive review. Int. J. Women's Dermatol. 2017, 3, 75-80. [CrossRef]

23. Bäumler, W. Absorption, distribution, metabolism and excretion of tattoo colorants and ingredients in mouse and man: The known and the unknown. Curr. Prob. Dermatol. 2015, 48, 176-184.

24. Wenzel, S.M.; Welzel, J.; Hafner, C.; Landthaler, M.; Bäumler, W. Permanent make-up colorants may cause severe skin reactions. Contact Dermat. 2010, 63, 223-227. [CrossRef]

25. Andreou, E.; Hatziantoniou, S.; Rallis, E.; Kefala, V. Legislation and Side Effects induced by Permanent Make Up Colors. Ep. Klin. Farmakol. Kai Farmakokinet. 2020, 38, 195-201.

26. Biskanaki, F.; Kefala, V. New strategies in Cosmetic Tattoo (Permanent Makeup) and Tattoo removal. Rev. Clin. Pharmacol. Pharmacokinetics. Int. Ed. 2018, 32, 17-21.

27. Guerra, E.; Llompart, M.; Garcia-Jares, C. Analysis of Dyes in Cosmetics: Challenges and Recent Developments. Cosmetics 2018, 5, 47. [CrossRef]

28. Schreiver, I.; Hutzler, C.; Andree, S.; Laux, P.; Luch, A. Identification and hazard prediction of tattoo pigments by means of pyrolysis-gas chromatography/mass spectrometry. Arch. Toxicol. 2016, 90, 1639-1650. [CrossRef]

29. Andreou, E.; Kefala, V.; Rallis, E. Why do cosmetic tattoos change color. An update. Rev. Clin. Pharmacol. Pharmakokinet. Int. Ed. 2018, 32, 115-123.

30. De Cuyper, C.; Lodewick, E.; Schreiver, I.; Hesse, B.; Seim, C.; Castillo-Michel, H.; Laux, P.; Luch, A. Are metals involved in tattoo-related hypersensitivity reactions? A case report. Contact Dermat. 2017, 77, 397-405. [CrossRef]

31. Zhang, M.; Jin, J.; Chang, Y.N.; Chang, X.; Xing, G. Toxicological properties of nanomaterials. J. Nanosci. Nanotechnol. 2014, 14, 717-729. [CrossRef]

32. IARC. Titanium dioxide. IARC Monogr. 2010, 93, 193-275.

33. Engel, E.; Santarelli, F.; Vasold, R. Modern tattoos cause high concentrations of hazardous pigments in skin. Contact Dermat. 2008, 58, 228-233. [CrossRef]

34. De Cuyper, C. Tattoo allergy. Can we identify the allergen? Presse Med. 2020, 49, 104047. [CrossRef]

35. Prior, G. Tattoo inks: Legislation, pigments, metals and chemical analysis. Curr. Probl. Dermatol. 2015, 48, 152-157.

36. Hauri, U. Inks for Tattoos and PMU (Permanent Make-Up)/Organic Pigments, Preservatives and Impurities Such as Primary Aromatic Amines and Nitrosamines; State Laboratory of the Canton of Basel-Stadt: Basel, Switzerland, 2011; pp. 1-10.

37. Bäumler, W.; Eibler, E.T.; Hohenleutner, U.; Sens, B.; Sauer, J.; Landthaler, M. Q-switch laser and tattoo pigments: First results of the chemical and photophysical analysis of 41 compounds. Lasers Surg. Med. 2000, 26, 13-21. [CrossRef]

38. Hogsberg, T.; Loeschner, K.; Lof, D.; Serup, J. Tattoo inks in general usage contain nanoparticles. Br. J. Dermatol. 2011, 165, 1210-1218. [CrossRef] [PubMed]

39. Bonadonna, L. Survey of studies on microbial contamination of marketed tattoo inks. Curr. Probl. Dermatol. 2015, 48, 190-195. [PubMed]

40. Nho, S.W.; Kim, S.J.; Kweon, O.; Howard, P.C.; Moon, M.S.; Sadrieh, N.K.; Cerniglia, C.E. Microbiological survey of commercial tattoo and permanent makeup inks available in the United States. J. Appl. Microbiol. 2018, 124, 1294-1302. [CrossRef]

41. Lehner, K.; Santarelli, F.; Vasold, R.; König, B.; Landthaler, M.; Bäumler, W. Black tattoo inks are a source of problematic substances such as dibutyl phthalate. Contact Dermat. 2011, 65, 231-238. [CrossRef] [PubMed]

42. Schreiver, I.; Hesse, B.; Seim, C.; Castillo-Michel, H.; Villanova, J.; Laux, P.; Dreiack, N.; Penning, R.; Tucoulou, R.; Cotte, M.; et al. Synchrotron-based $v$-XRF mapping and $\mu$-FTIR microscopy enable to look into the fate and effects of tattoo pigments in human skin. Sci. Rep. 2017, 7, 11395. [CrossRef]

43. Liszewski, W.; Warshaw, E.M. Pigments in American tattoo inks and their propensity to elicit allergic contact dermatitis. J. Am. Acad. Dermatol. 2019, 81, 379-385. [CrossRef] 
44. Wenzel, S.M.; Rittmann, I.; Landthaler, M.; Bäumler, W. Adverse reactions after tattooing: Review of the literature and comparison to results of a survey. Dermatology 2013, 226, 138-147. [CrossRef] [PubMed]

45. Ren, A.; Qiu, X.; Jin, L.; Ma, J.; Li, Z.; Zhang, L.; Zhu, H.; Finnell, R.H.; Zhu, T. Association of selected persistent organic pollutants in the placenta with the risk of neural tube defects. Proc. Nat. Acad. Sci. USA 2011, 108, 12770-12775. [CrossRef] [PubMed]

46. Heywood, W.; Patrick, K.; Smith, A.M.A.; Simpson, J.M.; Pitts, M.K.; Richters, J.; Shelley, J.M. Who Gets Tattoos? Demographic and Behavioral Correlates of Ever Being Tattooed in a Representative Sample of Men and Women. Ann. Epidemiol. 2012, 22, 51-56. [CrossRef]

47. Michel, R. Manufacturing of Tattoo Ink Products Today and in Future: Europe. Curr. Probl. Dermatol. 2015, 48, 103-111. [PubMed]

48. Council of Europe. Committee of Ministers: Resolution ResAP (2008)1 on Tattoos and Permanent Make-Up; Council of Europe: Strasbourg, France, 2008.

49. Eurofins-Chem-MAP. Available online: https://www.chem-map.com/chemical_news/seven-eu-member-states-introducenational-legislation-on-tattoo-ink-chemicals-and-permanent-make-up/ (accessed on 10 April 2021).

50. Cosmetic Products Regulation, Annex II-Prohibited Substances. Available online: https: / www.echa.europa.eu/web/guest/ cosmetics-prohibited-substances (accessed on 15 April 2021).

51. Brussels Times: EU to Tackle Hazardous Chemicals in Permanent Makeup and Tattoo Ink. Available online: https://www. brusselstimes.com/news/art-culture/146340/eu-to-tackle-hazardous-chemicals-in-permanent-makeup-and-tattoo-ink/ (accessed on 10 April 2021). 